\title{
IMPACT OF ENERGY EFFICIENCY MEASURES ON INDOOR AIR QUALITY IN BUILDING OF MECHANICAL ENGINEERING FACULTY SARAJEVO
}

\author{
Nurin Zečević, Azrudin Husika, Ejub Džaferović
}
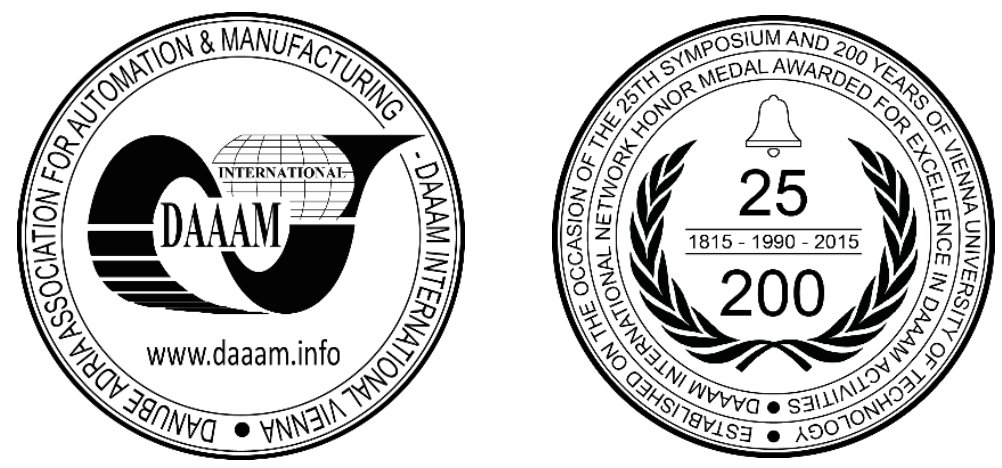

This Publication has to be referred as: Zecevic, N[urin]; Husika, A[zrudin] \& Dzaferovic, E[jub] (2018). Impact of Energy Efficiency Measures on Indoor Air Quality in Building of Mechanical Engineering Faculty Sarajevo, Proceedings of the 29th DAAAM International Symposium, pp.0197-0201, B. Katalinic (Ed.), Published by DAAAM International, ISBN 978-3-902734-20-4, ISSN 1726-9679, Vienna, Austria DOI: $10.2507 / 29$ th.daaam.proceedings.028

\begin{abstract}
The paper elaborates the results of measurement of indoor concentrations of carbon dioxide in the building of Mechanical Engineering Faculty Sarajevo (MEF) after implementation of energy efficiency measures. MEF's building was the first pilot project of energy efficiency in Bosnia and Herzegovina funded by UNDP and USAID in 2011. Among others, within the project, thermal insulation and efficient windows were installed on the building. As results of the measures, consumption of natural gas has been reduced $43 \%$ on annual basis. However, due to the lack of mechanical ventilation system in the building, energy efficiency measures have significant impact on indoor air quality (IAQ). In order to investigate this impact, measurements of IAQ parameters were performed in two classrooms in different period of day and week. Measurement of IAQ parameters have lasted for three weeks. The measurement sensor was installed on the wall 1,1 m above the floor, $1 \mathrm{~m}$ far from the occupants, on oposite side of the windows and door. Results of measurements showed that level of relative humidity is in acceptable range, corresponding to the standards for winter period when measurements were performed, but high concentration of carbon dioxide was recorded most of the time. Concentrations were very often high during the measurement periods, with the highest measured concentration of $2.598 \mathrm{ppm}$ during the lecture. In educational institutions, which relies on natural ventilation, daily carbon dioxide concentration should be less than 1500 ppm or 500 ppm above outside carbon dioxide concentration level.
\end{abstract}

Keywords: indoor air quality; carbon dioxide concentrations; energy efficiency; buildings; high schools

\section{Introduction}

Building sector is one of the largest energy consumers and implementation of energy efficiency measures represents potential for energy saving, reduction of fossil fuels and carbon emissions. Due to the non-optimal design of buildings, imperfect heating and cooling systems or insufficiently efficient energy management systems, energy consumption in practice is higher than the building itself demands [1]. Recent and emerging global standards in buildings dictate tight building envelopes, purposely limiting air infiltration with the aim of energy saving and reduction of carbon footprint. 
These measures also have the aim to reduce inside air pollutants, which is contradictory in the situation when implementation of energy efficiency measures deteriorates health and productivity of users [2]. Existing ventilation standards are usually minimum recommendations and optimal air quality mostly cannot be achieved in that manner, especially in the case when there is high occupancy. When users feel uncomfortable in their environment, they will take all necessary actions to achieve comfort for them, which can cause higher energy consumptions. Simply said, energy declaration without declaration related to the inside environmental quality does not make sense [3].

According to U.S.Environmental Protection Agency and Science Advisory Board (SAB), indoor air pollution is among first five environmental risks for users' health. In buildings if there is a lack of other pollutants, carbon dioxide is considered as the main indicator of ventilation productivity for control of the IAQ [4]. Carbon dioxide concentration is greater inside of the building than outside and when measured concentration of carbon dioxide is above $1000 \mathrm{ppm}$ in the area where only familiar source is exhaled air, it is assumed that cause is unadequate ventilation. On this level it does not present any danger for the user's health. But higher carbon dioxide concentration indicates the possibility of increasing other pollutants concentration, that can together in combination cause different health problems like headache, dizziness, iritation of the throat, nose, higher absence and medical expenses [5] [6].

Indoor air quality (IAQ) represents important part of every healthy environment and for educational buildings it contributes to the improvement of indoor environment, users' productivity, comfort, health and well-being. Educational buildings differ from other public buildings due to their role and great responsibility, educating future experts to raise social awareness with direct and indirect impact on local and global level. Because of that, energy performance of these buildings with good indoor air quality is of a great importance. Key aspects of methods that improve energy efficiency and indoor environment conditions in buildings should be concentrated on users health, productivity and achievement, energy reduction and impact on environment [7].

The concept of IAQ is quite broad and tests for analyzing and identifying inside pollutants are usually very expensive, complex and technically difficult. In majority of tests only some selected values are analyzed [7]. Digital equipment for carbon dioxide measurement is relatively economic and technical efficient way to determine carbon dioxide concentration as indicator of IAQ and efficiency of ventilation system and it can detect the problem before users are aware of it [4] [9]. With long-term carbon dioxide monitoring in combination with measurement of air temperature and relative humidity, building management can have better insight in supporting decision making about ventilation control and improving HVAC system, which can lead to greater energy savings, improved overall air quality and raising social awareness, necessary for successful achievement of high environmental standards [3]. IAQ is necessary requirement that needs to be fulfilled if there are high expectations from educational institutions [9].

\section{Methodology}

At the Mechanical Engineering Faculty Sarajevo, measurements of indoor air quality parameters were performed in two classrooms and one office. In this article, measurements in one classroom were being analyzed. MEF's building was the first pilot project of energy efficiency in Bosnia and Herzegovina funded by UNDP and USAID in 2011. Among others, within the project, thermal insulation and efficient windows were installed on the building. As results of the measures, consumption of natural gas has been reduced $43 \%$ on annual basis. However, due to the lack of mechanical ventilation system in the building, energy efficiency measures have significant impact on IAQ.

The classroom is located on the fourth floor of West building of Faculty with the room surface of $91 \mathrm{~m}^{2}$ and volume $498,84 \mathrm{~m}^{3}$. Orientation of the classroom is East. Classroom has sunshading protection in the form of manually operated portable panels. Beside natural ventilation, as mechanical ventilation, two air conditioners are used. Average number of students in one group was in the range 20-39 during measurements. Classroom was used 2 to 8 hours daily, depending on the the class schedule. Duration of one lecture is 45 minutes and 15 minutes for break between classes.

\section{Measurements}

The used measurement equipment is OPUS 20-TCO data logger, which was mounted on the wall $1,1 \mathrm{~m}$ above floor, $1 \mathrm{~m}$ far from the users and away from windows and door. The measuring range of carbon dioxide sensor was set to measure values of carbon dioxide concentration every 10 seconds and the readout values were shown every 60 seconds.

Measurements were performed in winter semester from $11^{\text {th }}$ November to $09^{\text {nd }}$ December 2016 and in summer semester from $8^{\text {th }}-29^{\text {th }}$ May 2017. Measurement lasted for three weeks per semester. The aim of performed measurements in two semesters was to compare measurement results in summer semester when the classroom is more ventilated with the results of winter semester when it is heating season on and windows are less opened. According to the standars for educational buildings, it is recommended that for educational building with natural ventilation, maximum carbon dioxide concentration should not exceed $1500 \mathrm{ppm}$ or according to the standard EN 15251 it should not exceed 500 ppm above outside carbon dioxide concentration level [10] [11].

\subsection{Measurement of IAQ parameters in winter semester (11.10.-09.12.2016)}

In Table 1. measurement results of IAQ parameters for winter semester are shown. Based on analysis of measured values of IAQ parameters (carbon dioxide, air temperature and relative humidity) for the classroom, it can be concluded there is presence of similar behavior model and characteristic features that influenced on the comfort conditions in the classroom during the lectures. 


\begin{tabular}{|c|c|c|c|c|}
\hline Measurement period & I & II & III & Average \\
\hline & & & & \\
\hline Max $\mathrm{CO}_{2}$ concentration (ppm) & 2598 & 1950 & 2384 & 2310 \\
\hline Average $\mathrm{CO}_{2}$ concentration (ppm) & 1323 & 1102 & 1280 & 1235 \\
\hline Air temperature (C) & 21 & 22 & 21 & 21 \\
\hline Relative humidity (\%) & 32 & 38 & 30 & 33 \\
\hline
\end{tabular}

Table 1. Measured values of IAQ parameters for three measurement periods in winter semester

Results of the measurements show that the average carbon dioxide concentration for the first measurement week was $1322 \mathrm{ppm}$, for the second week $1102 \mathrm{ppm}$ and for the third week $1280 \mathrm{ppm}$. Maximum values of carbon dioxide for all three periods were in the range from $1950-2598 \mathrm{ppm}$, with the average maximum value for all three periods $2310 \mathrm{ppm}$. It can be concluded that maximum measured carbon dioxide concentration was above the recommended value for about $50 \%$. Average air temperature for all three periods was in the range of $21-22^{\circ} \mathrm{C}$ and relative humidity was in the range from $25 \%$ to $39,2 \%$. Measured air temperature and relative humidity were in the range of recommended values for educational buildings, with the recommended air temperature of $20-21^{\circ} \mathrm{C}$ during winter period and relative humidity between $30-60 \%$ [11] [12]. During outside colder conditions, it is recommended that relative humidity should be below $30 \%$ to avoid condensation on the walls which further can cause the presence of funghi and mold [13].

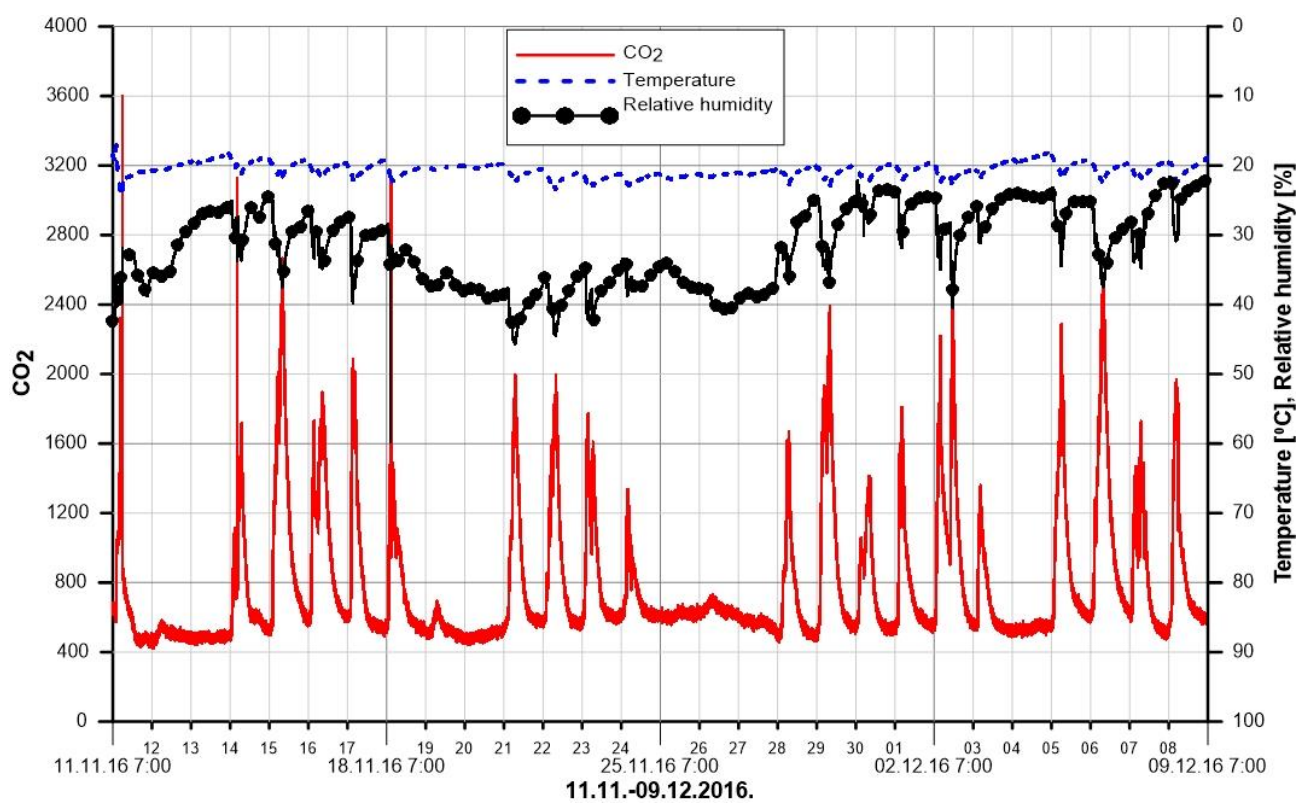

Fig. 1. Measurement results of IAQ parameters $\left(11^{\text {th }}-9^{\text {th }}\right.$ December 2016)

Comparing the measured values of carbon dioxide concentration, air temperature and relative humidity in winter semester, it can be concluded that graphic curves for all three measurement periods have similar character. Factors as number of occupants, class duration, using computers during the lectures, season, outiside climatic conditions and the frequency of ventilation influence on measurement values. Based on results from Figure 1, curve of carbon dioxide concentration has more „sharp“ character, with the constant rise of carbon dioxide concentration during the lectures, which peak on the graphic was mostly above $1600 \mathrm{ppm}$ and in some cases it reached value of 2400 ppm. Lower concentrations were achieved during the period of longer breaks and after the end of classes. In winter semester, slightly grow or decline of carbon dioxide concentration for about $50 \mathrm{ppm}$ was mostly because of shorter break between classes. During the heating season, classroom are much warmer than hallway and students are rarely leaving the classrooms. Average increase of carbon dioxide concentration during the lectures was 293 ppm and decline of the same $88 \mathrm{ppm}$. In the winter period, windows are rarely opened or they are not opened at all during the lectures. Based on results, six hours are necessary from the end of last class for carbon dioxide concentration to decline by 1052 ppm on acceptable value of $720 \mathrm{ppm}$. Usually, that value is achieved in the late evening hours.

\subsection{Measurement of IAQ parameters in summer semester (08.05.-29.05.2017)}

In the summer semester, measurement of IAQ parameters was performed with the aim to compare measurement results of two different seasons from the aspect of the external climatic conditions. During the measurement period, air conditioners did not work and ventilation was natural. In Table 2. measurement results of IAQ parameters for summer semester are summerized. 


\begin{tabular}{|c|c|c|c|c|}
\hline Measurement period & I & II & III & Average \\
\hline & & & & \\
\hline Max $\mathrm{CO}_{2}$ concentration (ppm) & 1407 & 1461 & 1909 & 1592 \\
\hline Average $\mathrm{CO}_{2}$ concentration (ppm) & 882 & 812 & 901 & 965 \\
\hline Air temperature (C) & 24 & 26 & 26 & 25 \\
\hline Relative humidity (\%) & 35 & 38 & 46 & 39 \\
\hline
\end{tabular}

Table 2. Measured values of IAQ parameters for three measurement period in summer semester

Results of measurements show that the average carbon dioxde concentration was in the range from 653-1124 ppm during all three periods. Maximum measured carbon dioxide values for all three periods were in the range 817-1909 ppm. On Monday of the third measurement week, with the class beginning at 9:15 h, continuous rise of carbon dioxide concentration was recorded. During the first class, concentration increased for $692 \mathrm{ppm}$ and during the break, it continued to increase for $170 \mathrm{ppm}$. At the end of break, measured carbon dioxide concentration was $1609 \mathrm{ppm}$. During second class, concentration achieved the value of $1909 \mathrm{ppm}$ which is the maximum measured value for all three measurement periods. Based on the results, it can be concluded that there was not usual break between classes and the classroom was not ventilated during the lectures. After the end of class, during the next break, carbon dioxide concentration decreased for $783 \mathrm{ppm}$, more precisely $1126 \mathrm{ppm}$ after students left the classroom and windows were opened.

In the second measurement period, the lowest increase of carbon dioxide concentration during lectures was recorded (90 ppm) in comparance with the measurement results of two other periods. This is the period when academic stuff purporsely have opened the windows to ventilate the classroom. Average air temperature for all three periods was in the range of recommended values $24,1-26^{\circ} \mathrm{C}$ and relative humidity was in the range $24,3-38,9 \%$.

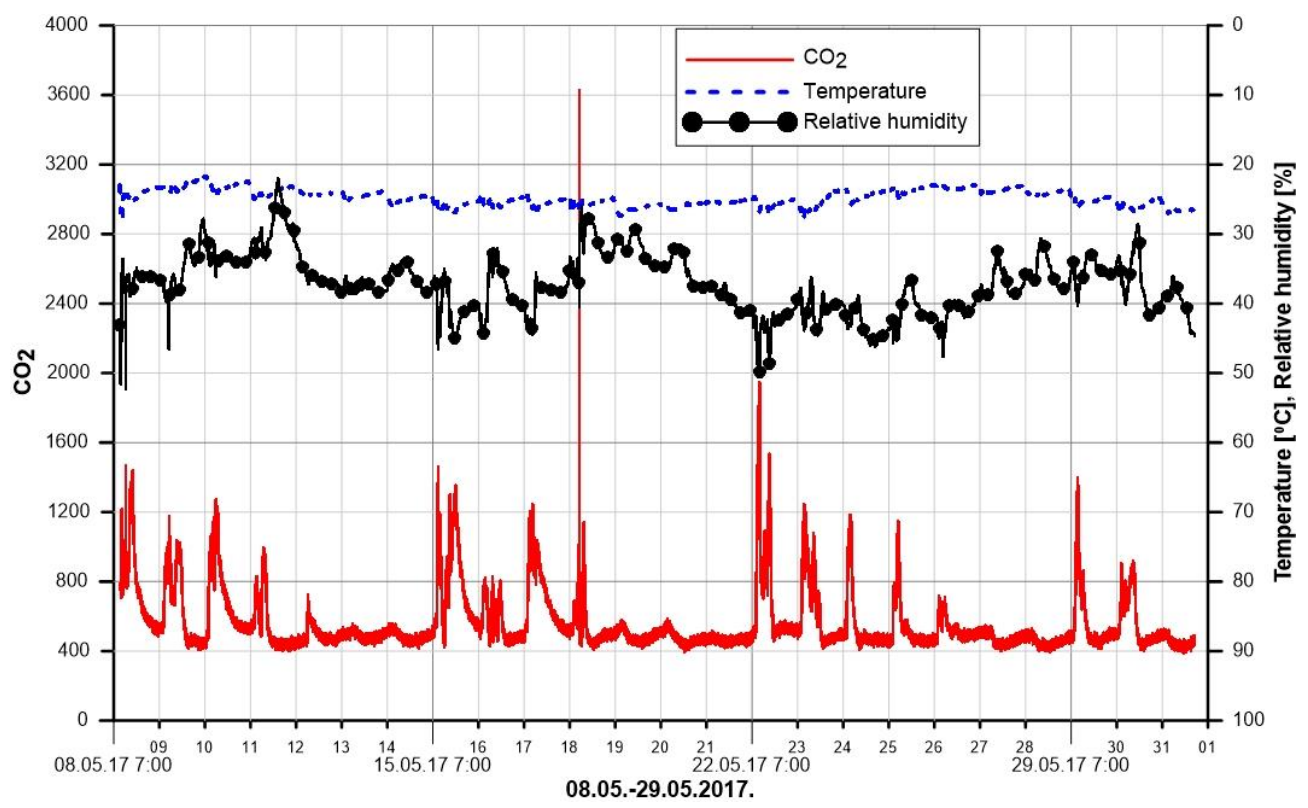

Fig. 2. Measurement results of IAQ parameters $\left(8^{\text {th }}-29^{\text {th }}\right.$ May 2017)

Measurement results from Figure 2. show that the character of curves for summer semester is „smoother“ comparing to the winter semester, where the peak averagely reached the value of $1200 \mathrm{ppm}$ in dependance to the number of students and room ventilation. Average increase of carbon dioxide concentraction during the mid of lectures was 147 ppm and decrease of the same till the end of the class was $220 \mathrm{ppm}$. In summer semester, it takes about 2,5 hours from the end of the last class to fall carbon dioxide concentration on the accetable value from $600 \mathrm{ppm}$.

\section{Conclusion}

Measurement results indicate that because of lack of adeuqate ventilation, carbon dioxide concentration was very often high during the measurement periods in the winter semester. Comparing maximum measured values of the carbon dioxide concentrations in winter and summer semester, maximum values in winter period exceeded $60 \%$ of the recommended values. In educational institutions, which relies on natural ventilation, daily carbon dioxide concentration should be less than $1500 \mathrm{ppm}$ or $500 \mathrm{ppm}$ above outside carbon dioxide level. In summer semester, although there was a rise of carbon dioxide concentration during the lectures, because of frequent opening the windows during the lectures, concentration decreased by two or more times comparing to the increaseament of the same till the end of the class. 
Windows are less opened during the winter time because of higher temperature differences and themal comfort represents priority in comparance with the indoor air quality. Natural ventilation during winter period is one way to decrease carbon dioxide concentration but it does not represent ideal solution for ventilation causing possible discomfort with the introduce of the cold air. During summer semester, measurement was performed in May when outside temperatures are more comfortable and do not have high impact on overheating of the classroom. With the natural ventilation, it is possible to provide optimal air temperature and to change stale air by introducing new, fresh air. Air temperature was mostly influenced by classroom occupation and heating system schedule, and most of the time average air temperature in the classroom was between $21-22^{\circ} \mathrm{C}$. Measured relative humidity was in the range of recommended values. During very cold outside conditions, relative humidity should be below $30 \%$ to avoid condensation on the walls and windows which further cause the presence of funghi and mold.

Although implementation of energy efficiency measures on buildings results with energy savings and reduction of carbon dioxide, human with its behaviour can influence on the same factors, improving or worsening them. Measurement results at Mechanical Engineering faculty represent significant review of human influence on IAQ and control of the same. Measurement in second classroom showed that left opened windows after the end of the class on Friday, led to significant decrease of inside air temperature from $24^{\circ} \mathrm{C}$ to $0,9^{\circ} \mathrm{C}$. On Monday, air temperature at the beginning of the lecture was $9^{\circ} \mathrm{C}$. Such unconscionable behaviour led to the energy losses and inadequate inside conditions. Result of measurements performed at administration office at Mechanical Engineering Faculty showed that average carbon dioxide concentrations exceeded by $45 \%$ recommended values, with the highest measured carbon dioxide concentration of $2600 \mathrm{ppm}$. It is mostly related with the thermal comfort, which has higher priority than indoor air quality at winter period, with the risk of higher carbon dioxide concentration. Users need to be more aware of their important role in energy savings without compromising thermal comfort and IAQ.

Aim of measurements IAQ parameters at Mechanical Engineering Faculty Sarajevo is to emphasize influence of energy efficiency measures on carbon dixode concentration and possible impact on productivity, health and performance of users. In Bosnia and Herzegovina, importance of IAQ is not in the focus of social interest as it should be, especially because people spend most of they time in the buildings and they are in constant contact with the inside ambiental conditions. Every building should be designed and build without comprimising the health and productivity of users. It can be achieved with the good planned energy concept as optimal and integral solution based on sustainablity through construction quality, improving thermal insulation of the building, use of modern energy systems and renewable energy technologies, rational use of energy, improvement of IAQ through respecting recommended standards and demands. Optimal ventilation system should be inconsiderable part of every energy measurement strategy, with the aim to provide fresh air, remove air pollutants and achieve good indoor quality because health and productivity of students should be main criteria for every designer, building management and community. As part of energy efficiency methodology, it is necessary to plan, follow and respect integrated path to achieve well planned energy building concept without deterioration of indoor air quality. In this context, modeling of impacts of possible measures, which can be implemented on refurbished public buildings, aiming mitigation of indoor carbon dioxide concentrations will be implemented.

\section{References}

[1] Crnokić, B,; Lješić, G,; Stojkić, Ž,; Bandić Glavaš, M. (2017). Comparison of energy consumption parameters obtained from the energy dynamic model of the building and actual energy consumption parameters, Proceedings of the 28th DAAAM International Symposium, DOI: 10.2507/28th.daaam.proceedings

[2] Lowitz, G. (2015). Managing Carbon-Dioxide Risk: What You Should Know, ONSET HOBO,

[3] Olesen, W.B. (n.d.). Revision of EN 15251: Indoor Enviromental criteria, International Centre for Indoor Enviroment and Energy, Departmen of Civil Engineering, Technical University of Denmark

[4] United States Enviromental Protection Agency (EPA). Why Indoor Air Quality is important to Schools

[5] Berardinelli S.Jr. „HHE Report - South Junior High School“. (1992). HETA 92-138-2258, West Virginia

[6] Kats, G. (2006). Greening America's Schools: Costs and benefits, A Capital E.Reports

[7] Schneider Electric, (2009). Building intelligence in schools

[8] Sowa J. (2009). Air quality and Ventilation rates in Poland - Requirements, Reality and Possible improvements, Proceedings:Indoor Air

[9] SST Sensing Ltd. (n.d.). The Importance of Monitoring CO2 Levels in Classroom

[10] Lazović I.M.; Stevanović Ž.M.; Jovašević-Stojanović M.V.; Živković M.M \& Banjac M.J. (2016). Impact of CO2 concentation on Indoor Air Quality and correlation with relative humidity and indoor air temperature in school buildings in Serbia, THERMAL SCIENCE, Vol.20, Suppl 1., pp 297-2307

[11] Berardinelli, S. Jr. (1992). HHE Report - South Junior High School, HETA 92-138-2258, West Virginia

[12] CEN/TC 156. (2006). Indoor enviromental input parameters for design and assessment of energy performance of buildings-addressing indoor air quality, thermal enviroment, lighting and acoustics, Final Draft EN 15251

[13] Government of Alberta (2009). Indoor Air Quality Tool Kit, Work safe Alberta, Employment and Immigration 